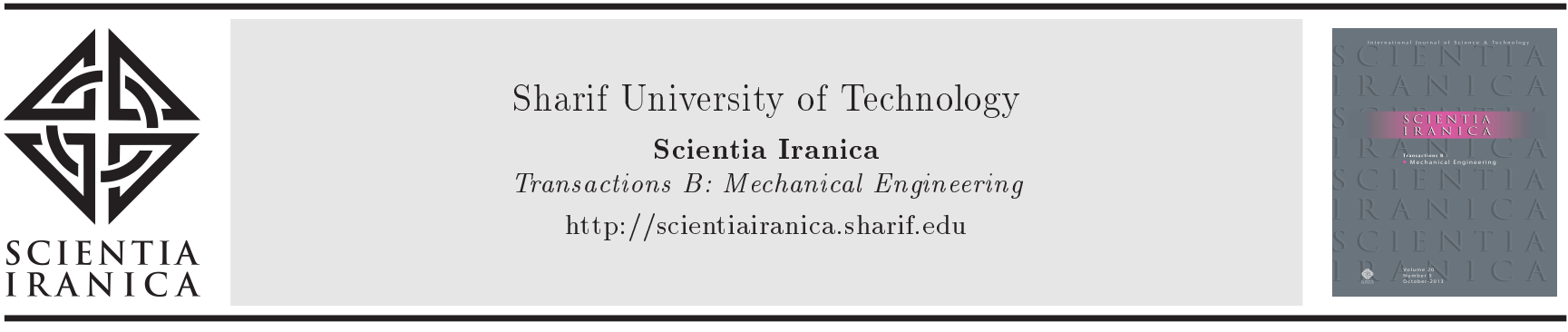

\title{
Rolling contact fatigue analysis of rails under the influence of residual stresses induced by manufacturing
}

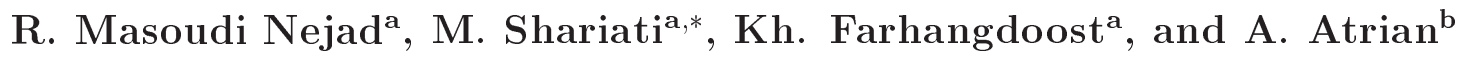 \\ a. Faculty of Engineering, Department of Mechanical Engineering, Ferdowsi University of Mashhad, Mashhad, Iran. \\ b. Department of Mechanical Engineering, Najafabad Branch, Islamic Azad University, Najafabad, Iran. \\ Received 4 December 2017; received in revised form 13 January 2018; accepted 17 February 2018
}

\author{
KEYWORDS \\ Rolling contact \\ fatigue; \\ Manufacturing \\ process; \\ Finite element; \\ Fatigue crack growth; \\ Boundary element.
}

\begin{abstract}
This study aims to analyze the rolling contact fatigue susceptible to residual stresses caused by the contact between the wheel and rail and its manufacturing process. For this purpose, a rail available in Iran railway is used with an exact profile geometry. The location of maximum stress caused by the contact of wheel/rail for rail profiles can be calculated by a three-dimensional elastic-plastic finite element model. Then, in order to estimate the stress distribution in the rail manufacturing process, a thermal analysis with a finite element method will be performed. Afterward, the results of the performed stress analysis will be used as inputs for three-dimensional crack growth and rail fatigue life estimation model to calculate the stress intensity factors and fatigue life according to a set of parameters related to the boundary element method. Finally, three-dimensional finite element analysis results obtained show good agreement with those achieved in field measurements.
\end{abstract}

(C) 2019 Sharif University of Technology. All rights reserved.

\section{Introduction}

In the case of transfer of contact forces from rail to the wheel and therefrom to the wagon, the condition of the railways can play an important role in fatigue life of these parts. The contact force between rail and wheel affects the fatigue life to a large extent. These forces, affected by the geometry of rail and wheel, are dependent on the frictional and slippage attributes of wheel/rail and their material. By considering the importance of careful analysis of these forces and the effect of residual stress in the manufacturing process of wheel and rail on the amount of these forces at the location of contact, the application of numeral methods in this matter is of utmost importance [1-3].

There have been many attempts regarding the

\footnotetext{
*. Corresponding author.

E-mail address: mshariati44@um.ac.ir (M. Shariati)
}

study of residual stresses [4-8]. Ringsberg et al. first analyzed how residual stresses affected rail's service life, which is the same as fatigue crack growth time. Finite element analysis was used to construct the twodimensional analytical model of cold iron rail and smoothen rolling [9]. Skyttebol et al. studied the residual stresses in rails caused by welding operation on fatigue crack growth. They studied the impact of the wheel movement on the growth of studied crack while considering the effect of the residual stresses. The effects of load parameters on the axle, crack location, and its size were also studied. The results showed that the effect of thermal stress was indeed significantly important; of course, the size of the crack and its growth was also notable [10].

There have been many research studies in the area of studying effective parameters in fatigue crack growth such as the initial crack angle and type of load [11-14]. In the area of railways, Wong et al. studied shallow and angled cracks, which would turn into holes or traverse under certain circumstances. Since the cracks that 
are getting deeper are more dangerous, they continued their research on such cracks [15]. Murakami et al. investigated the mechanisms that cause fatigue crack to grow. The results show that fatigue causes a crack to grow not only towards the direction of load, but also in the direction opposite to the load; however, in comparison, its growth towards the opposite side is not that much visible [16]. Chung et al. studied the appearance of holes phenomenon due to contact stresses and investigated the effect of the following parameters: initial crack length, initial crack angle, contact pressure, and hydraulic pressure. By using the two-dimensional finite element model, stress intensity factors of Modes I and II were calculated; afterward, the strain energy theory was employed to show that the cracks were probably transformed into holes under these conditions. The results were then compared with the available experimental results [17].

Masoudi Nejad has carried out extensive research studies in the area of fatigue crack growth under the influence of residual stresses in bandaged wheels. Masoudi Nejad et al. studied the fatigue crack growth and estimated bandage wheel life under the influence of contact stresses and residual stresses in the manufacturing process. Based on the results of this research, the growth of fatigue crack into the wheel of Iran railway without residual stresses is an indication of crack growth mode as the mixed shearing Modes of II and III [18-20]. In another study, Masoudi Nejad reviewed stress field in railway wheel caused by the manufacturing process. For this purpose, the threedimensional elastic-plastic finite element model was proposed to estimate the stress field. The comparison of the results of this research and field observation available in sources shows that they are similar to an acceptable degree [21].

Most attempts in this area have been made in order to predict crack initiation. Some other works have been also carried out on fatigue crack growth. However, not much attention has been paid to fatigue crack growth in the case of the Iran railway and residual stresses. In this paper, with regard to available parameters in Iran railway, first, the residual stresses in the manufacturing process and utilization of railway crack were simulated; then, the results were used as input for fatigue crack growth with a boundary element method.

\section{Residual stress field}

\subsection{Residual stress field caused by wheel/rail contact}

To simulate residual stresses and the wheel/rail contact, the finite element model was used for modeling purposes. Dynamic forces on each wheel in this analysis were of $120 \mathrm{kN}$, and the applied torque was 101 N.m. In wheel/rail contact modeling, in order to calculate the stress distribution, the location of contact between rail and wheel will be located $70 \mathrm{~mm}$ from the inner edge of flanges. The length of the modeled rail is the length of the rail between two traverses and is equal to $600 \mathrm{~mm}$. Wheels' degree of freedom in the direction of applied force is not limited, yet is completely restricted towards the two other directions. Moreover, on both sides of the rail, a completely tangled boundary condition is applied. Wheel/rail interactions are arranged as a surface-to-surface contact type. Details of different stages of different modeling and solving wheel/rail contact problems by the finite element model are in accordance with those of [4]. In the case of fine meshing of wheel, rail surface was chosen as the main surface, and the surface of the wheel's head was chosen as the secondary surface. One of these two surfaces shall be chosen as the target surface and the other as the contact surface; as for this study, the surface of the rail head was chosen as the target and wheel's fellow as the contact surface due to its fine meshing. In order to analyze wheel/rail contact friction, material's friction rate is assumed to be 0.3 in all directions [2]. The 3D elastic-plastic finite element model of the contact between wheel and rail is shown in Figure 1 . Mechanical properties of rail and wheel are available in Table 1. Table 2 shows the finite-element solution according to the number of elements, and maximum von-Mises stress for wheel and rail profiles is also presented. In addition, the most appropriate number of wheels is 59441; as for the rail, it is 29456. Based on the results of finite-element analysis, the amount of von Mises stress equals $518 \mathrm{MPa}$. Figure 2 illustrates the stresses caused by wheel/rail contact.

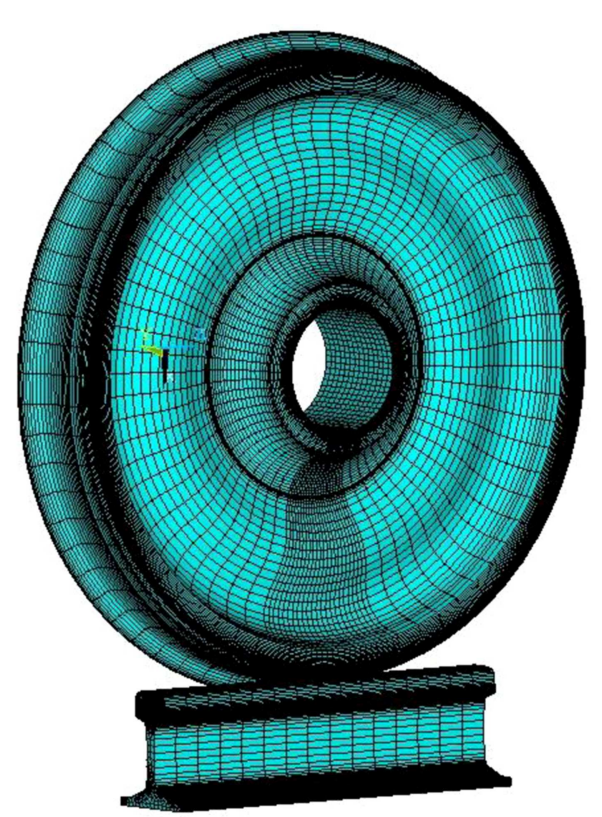

Figure 1. Finite element modeling of wheel/rail contact. 
Table 1. Mechanical properties of wheel and rail [2].

\begin{tabular}{cccc}
\hline Component & $\begin{array}{c}\text { Elastic module } \\
(\mathbf{G P a})\end{array}$ & $\begin{array}{c}\text { Poisson's } \\
\text { ratio }\end{array}$ & $\begin{array}{c}\text { Yield stress } \\
\text { (MPa) }\end{array}$ \\
\hline Wheel & 205 & 0.3 & 527 \\
Rail & 206.9 & 0.295 & 483 \\
\hline
\end{tabular}

Table 2. Finite element results of different elements for wheel and rail.

\begin{tabular}{cccc}
\hline Step & $\begin{array}{c}\text { Number of } \\
\text { rail elemnts }\end{array}$ & $\begin{array}{c}\text { Number of } \\
\text { wheel elements }\end{array}$ & $\begin{array}{c}\text { Maximum von-Mises } \\
\text { stress (MPa) }\end{array}$ \\
\hline 1 & 6155 & 17841 & 367 \\
2 & 8911 & 24312 & 413 \\
3 & 10365 & 30808 & 443 \\
4 & 13421 & 37012 & 457 \\
5 & 18512 & 41872 & 485 \\
6 & 24109 & 48547 & 493 \\
7 & 27783 & 52811 & 512 \\
8 & 29456 & 59441 & 518 \\
9 & 32543 & 61178 & 518 \\
\hline
\end{tabular}

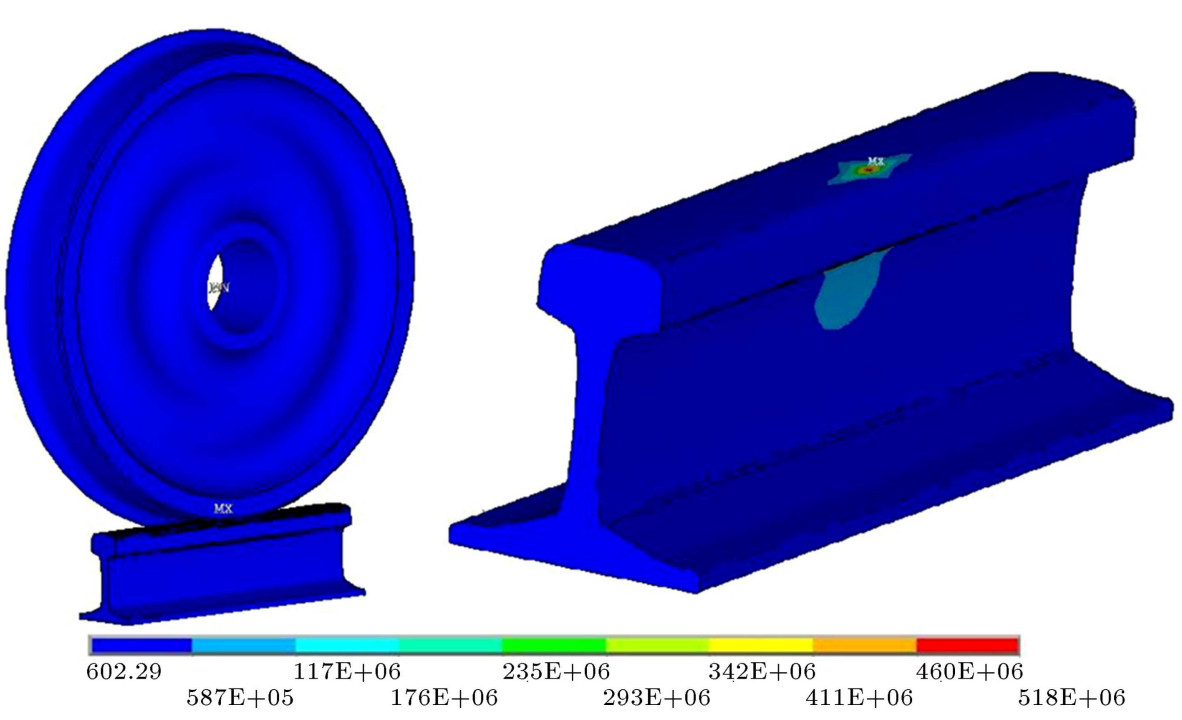

Figure 2. Von Mises stress caused by wheel/rail contact.

\subsection{Residual stress field in the manufacturing process}

In order to reduce the risk of crack formation on rail surface in the manufacturing process, a thermal operation is performed to increase the surface rigidity. Figure 3 shows the finite element modeling of rail in the manufacturing process for residual stress analysis. All other parameters, such as material properties, boundary conditions, meshing, and methods for the model, are defined according to [21].

Residual stresses created on the surface of the rail due to different thermal loads during thermal operation are of great importance. They change because of mechanical stress caused by the operation. The aim of various research studies on the manufacturing process is to demonstrate the residual stresses on the surface of elements. Figure 4 illustrates the stress distribution caused by the manufacturing process. For railway rail, the magnitude of von Mises stress appears to be 639 $\mathrm{MPa}$ after this heat treatment.

\section{Stress intensity factor and rail life estimation}

Crack growth in rail under the influence of stress field caused by wheel/rail contact in the manufacturing process with the boundary element method will be discussed. In addition, three samples of the existing 


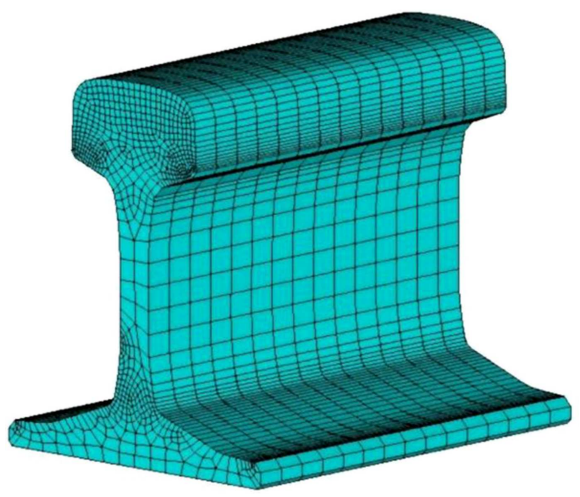

Figure 3. Finite element modeling of rail for thermal analysis.

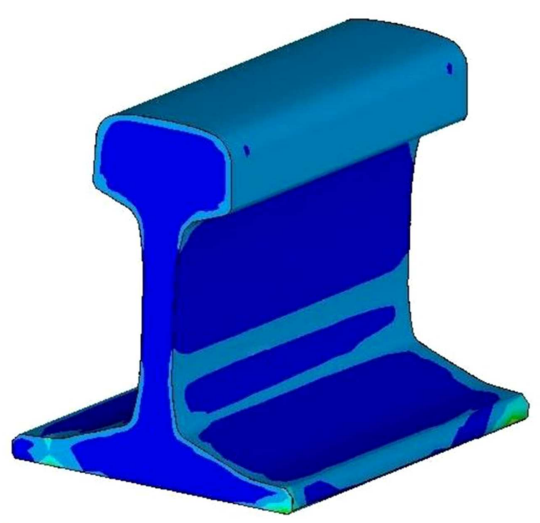

$269 \mathrm{E}+04 \quad 144 \mathrm{E}+06 \quad 285 \mathrm{E}+06 \quad 427 \mathrm{E}+06 \quad 568 \mathrm{E}+06$

$734 \mathrm{E}+05 \quad 215 \mathrm{E}+06 \quad 356 \mathrm{E}+06 \quad 497 \mathrm{E}+06 \quad 639 \mathrm{E}+06$

Figure 4. Von Mises stress in the manufacturing process of rail analysis.

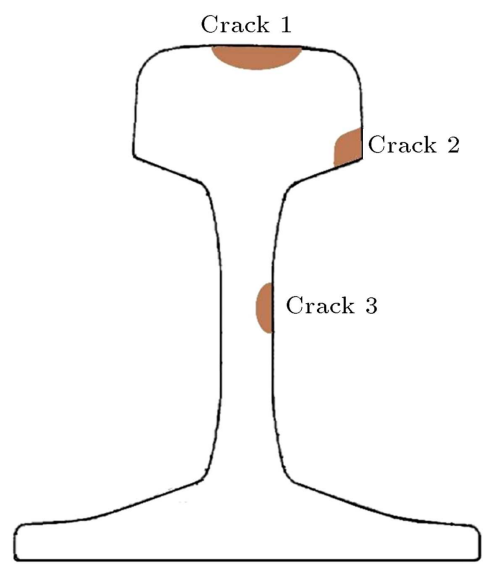

Figure 5. The positions of the studied cracks.

cracks in railway rail will be studied: crack in rail head, crack in rail web, and crack in rail plate (Figure 5).

In order to simulate fatigue crack growth and estimate fatigue life in rails, modeling was done by Franc 3D software, which is designed by researchers at Cornell University. A real rail with cracks is illustrated through the boundary element model in Figure 6 .
As can be seen in Figure 6(c), smaller partitioning was applied in order to achieve more accurate results around the crack. In this study, Cracks 1 and 3 are considered to be semi-elliptical (Figure $7(\mathrm{a})$ ); as for Cracks 2, it is considered to be quarter-elliptical (Figure $7(\mathrm{~b}))$. The dimensions of the initial crack shown in Figure 7 are $a=0.5 \mathrm{~mm}$ and $b=1 \mathrm{~mm}$.

The next stages of the finite element model, including specifying material properties, meshing, boundary conditions, and model-solving, are performed and mentioned below. The forces that are applied to the rails include the vertical force by the train weight, and the other force is the rolling resistance force that enters the rails as the train passes through the wheels. This force is caused by the rolling friction force that is applied to the surface of cracks, making them slide on each other. After loading, the element part is meshed and, then, the stress analysis is performed via "BES" software. Afterward, the values of the stress intensity factors are calculated for each of the three modes. Once the values of stress intensity factors are available, the crack growth direction can be predicted and crack growth rate becomes ideal. When the direction of the crack growth is recognized, the crack tip curve can be formed in its exact place and the crack can grow by one level. In order for the crack to grow through the boundary element method, first, the tip of the crack should be divided into a certain number of elements. It is up to the user to decide the number of divisions. These crack divisions are schematically illustrated in Figure 8(a). Then, a hypothetical plane is placed on each of these newly created groups. This plane is perpendicular to the crack front side on the intended point. Polar coordinates are then used to calculate the stresses and displacements. This plane and the intended coordinate system are depicted in Figure 8(b).

Displacement vectors and polar coordinate are depicted in Figure 9. Displacement values are drawn via finite element relations; then, the stress intensity factors are calculated based on these relations. Displacement values are calculated through Equation 1.

$$
\begin{aligned}
\left\{\begin{array}{l}
u \\
\nu
\end{array}\right\}= & 2(1+\nu) \frac{K_{I}}{E} \sqrt{\frac{r}{2 \pi}} \\
& \left\{\begin{array}{c}
\cos \frac{\theta}{2}\left[1-2 \nu+\sin ^{2} \frac{\theta}{2}\right] \\
\sin \frac{\theta}{2}\left[2-2 \nu+\cos ^{2} \frac{\theta}{2}\right]
\end{array}\right\} \\
& +2(1+\nu) \frac{K_{I I}}{E} \sqrt{\frac{r}{2 \pi}} \\
& \left\{\begin{array}{c}
\sin \frac{\theta}{2}\left[2-2 \nu+\cos ^{2} \frac{\theta}{2}\right] \\
\cos \frac{\theta}{2}\left[-1+2 \nu+\sin ^{2} \frac{\theta}{2}\right]
\end{array}\right\} .
\end{aligned}
$$




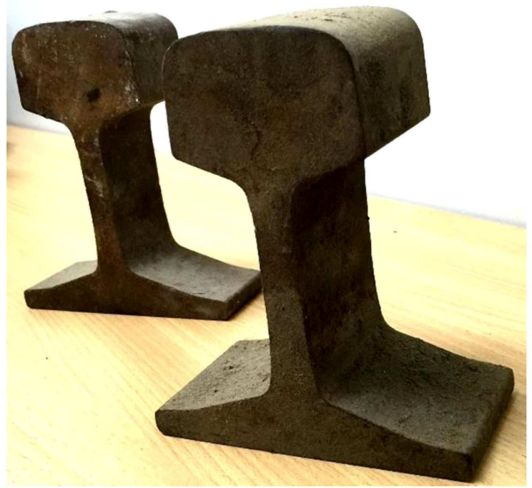

(a)

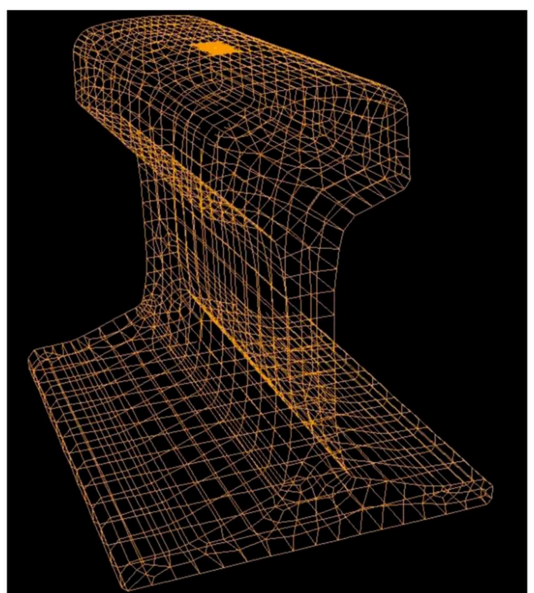

(b)

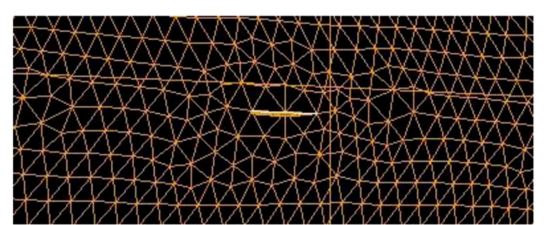

(c)

Figure 6. (a) Geometry of rail. (b) Meshed geometry of rail for analysis through boundary element method. (c) Meshing of crack surface.

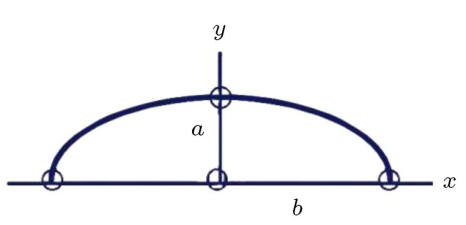

(a)

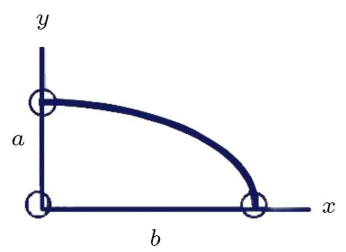

(b)

Figure 7. Initial crack length: (a) Semi-elliptical crack and (b) quarter-elliptical crack.

In order to find the direction of crack growth, the maximum circumferential stress criterion should be used. According to this criterion, the crack grows toward the direction where $\sigma_{\theta \theta}$ is at maximum; in other words, $\sigma_{\theta \theta}=0$. In this case, $\sigma_{\theta \theta}$ is calculated through Eq. (2):

$$
\begin{aligned}
\sigma_{r \theta}= & \frac{K_{I}}{\sqrt{2 \pi r}} \sin \frac{\theta}{2} \cos ^{2} \frac{\theta}{2} \\
& +\frac{K_{I I}}{\sqrt{2 \pi r}}\left(\frac{1}{4} \cos \frac{\theta}{2}+\frac{3}{4} \cos \frac{3 \theta}{2}\right) .
\end{aligned}
$$

Here:

$$
\tan \frac{\theta_{0}}{2}=\frac{1}{4} \frac{K_{I}}{K_{I I}} \pm \frac{1}{4} \sqrt{\left(\frac{K_{I}}{K_{I I}}\right)^{2}+8}
$$

In this way, the direction of crack growth is recognized. The extent to which the crack length increases can be calculated through Eq. (4).

$$
a_{i}=a_{\max }\left[\frac{K_{I}}{K_{I \max }}\right]^{b},
$$

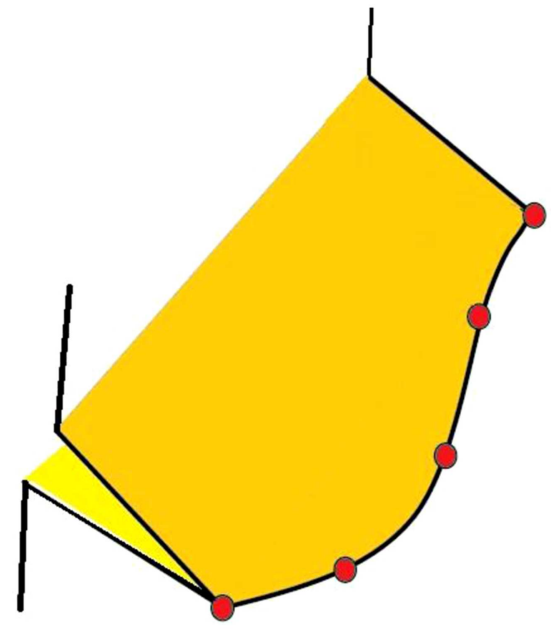

(a)

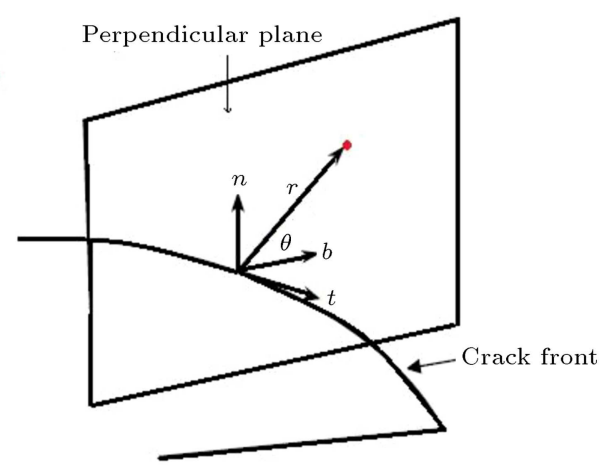

(b)

Figure 8. (a) Divisions on crack front side. (b) Hypothetical plane in front of crack. 


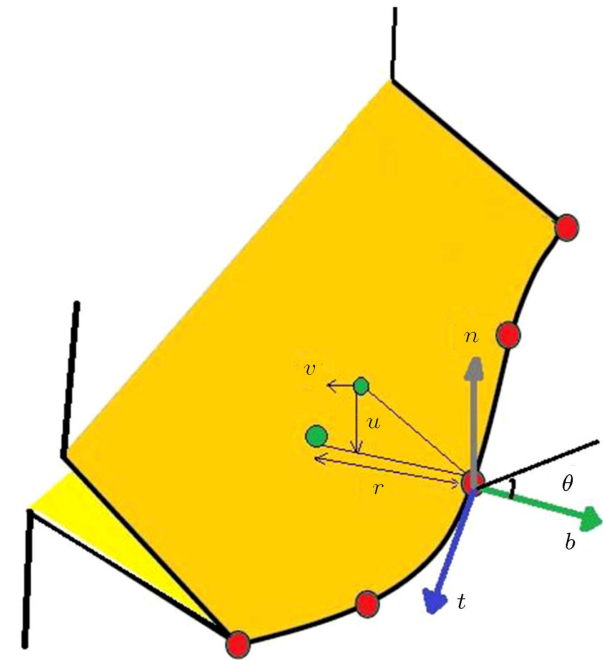

Figure 9. Polar coordinates used to divide the crack tip.

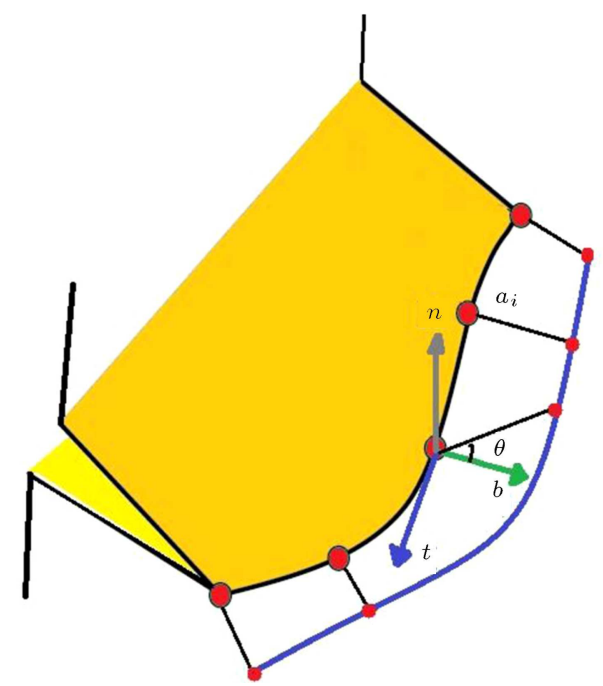

Figure 10. Crack growth and a new curved crack front.

where $a_{\max }$ is specified by the user. The power of $b$ is also determined by the user, and its value is usually equal to the power of Paris equation. Crack growth and the new curved crack front are illustrated in Figure 10.

Once the crack grows, the part that is meshed again is prepared to be solved. This is repeated for each stage until the crack is grown up to the desired value. Figure 11 illustrates the crack after 6 growth stages.

The crack was once again analyzed while applying stress distribution. Crack is grown for 22 stages until it reaches the critical point, i.e., $42 \mathrm{~mm}$, leading to failure in the end. Then, once the necessary data are entered and the values of the stress intensity factor are calculated, fatigue life is calculated for the intended rail. In order to determine the crack growth rate and fatigue life, the existing equations [22-23] might be used. In this study, the modified equation of Paris

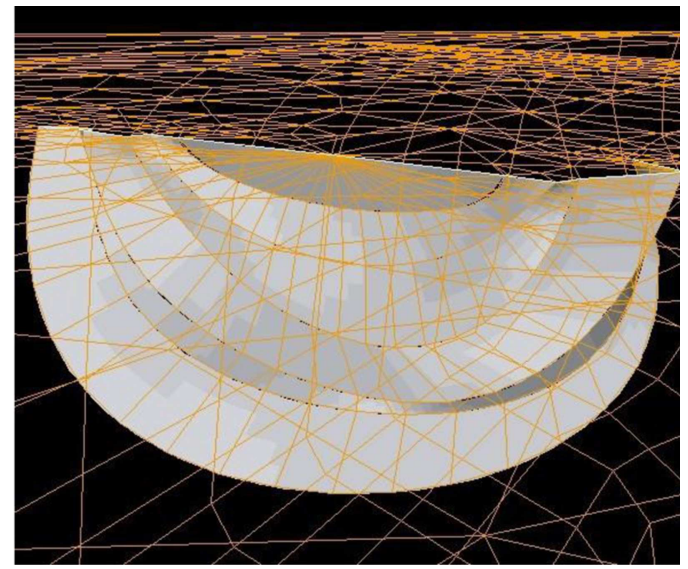

Figure 11. Crack after 6 stages of growth.

is used that also takes into account the effects caused by fatigue crack closure. Based on this equation, the growth rate is defined as follows [24]:

$$
\frac{d a}{d N}=C\left(\Delta K_{e f f}\right)^{n}=C\left(K_{\max }-K_{o p}\right)^{n}
$$

In the above-mentioned equation, $\Delta K_{e f f}$ is the effective stress intensity factor and is equal to $K_{\max }$ maximum stress intensity factor and the stress level required for crack opening, $K_{o p}$. Also, $C$ and $n$ factors in this equation are material constants and are, respectively, considered to be $4.25 \times 10^{-9} \mathrm{~m} /$ cycle and 3.14 in this paper. Crack-opening-stress function, $f$, is defined for plastic crack closure as follows $[25,26]$ :

$$
\begin{aligned}
& f=\frac{K_{o p}}{K_{\max }}= \\
& \begin{cases}\max \left(R, A_{0}+A_{1} R+A_{2} R^{2}+A_{3} R^{3}\right) & R \geq 0 \\
A_{0}+A_{1} R & -2 \leq R<0\end{cases}
\end{aligned}
$$

In addition, the factors for the above-mentioned equation are calculated as follows:

$$
\begin{aligned}
& A_{0}=\left(0.825-0.34 \alpha+0.05 \alpha^{2}\right)\left[\cos \left(\frac{\pi}{2} S_{\max } / \sigma_{0}\right)\right]^{\frac{1}{\alpha}} \\
& A_{1}=(0.415-0.071 \alpha) \frac{S_{\max }}{\sigma_{0}} \\
& A_{2}=1-A_{0}-A_{1}-A_{3} \\
& A_{3}=2 A_{0}+A_{1}-1
\end{aligned}
$$

In these equations, $\alpha$ is the finite factor for the plane stress-strain condition, and $S_{\max } / \sigma_{0}$ is the ratio of maximum stress applied to stress flow (the stress required to initiate plastic flow). 


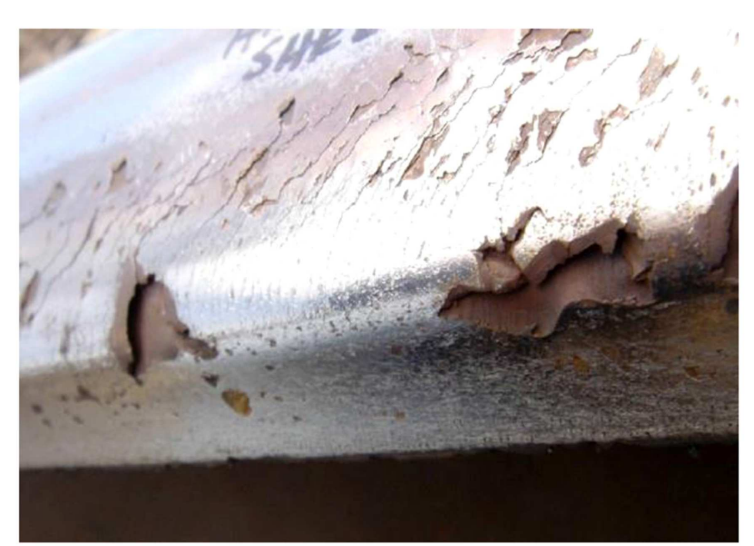

(a)

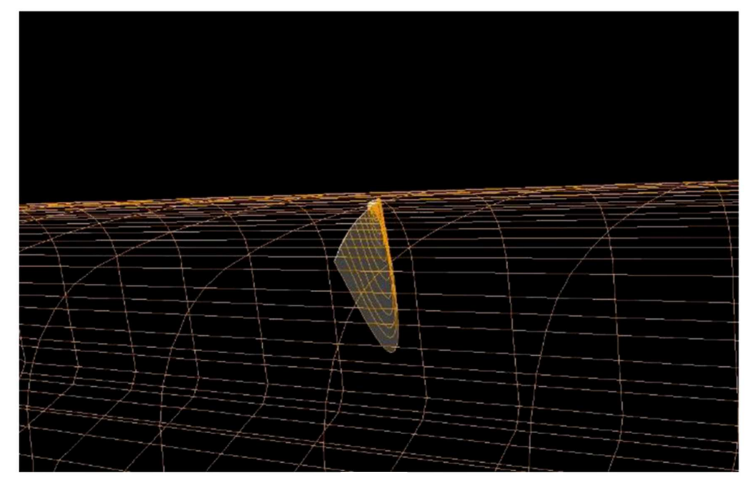

(b)

Figure 12. (a) Field observation [27] and (b) numerical analysis of rail failure.

The number of cycles required for crack growth from the initial length, $a_{0}$, to the final crack length, $a_{f}$, is presented in Eq. (11):

$$
N_{t o t}=\int_{a_{0}}^{a_{f}} \frac{d a}{C\left(\Delta K_{e f f}\right)} .
$$

As can be seen in Figure 12, crack growth prediction by Franc 3D software shows good agreement with those achieved in field observation [27].

\section{Results and discussion}

Results of the stress intensity factors of Mode I for tips cracks (1, 2, and 3) are illustrated, respectively, in Figure 13. As can be seen, the stress intensity factor of Mode I in the presence of residual stresses in the manufacturing process is a positive value and has a noticeable impact on crack growth in rail. An increase in crack length is an aggravating factor of the current condition. Therefore, as the crack length increases, the values of the stress intensity factor of Mode I increase, too; thus, the maximum Mode-I stress intensity factor of Crack 1 for the initial crack growth will be $10 \mathrm{~mm}$.

Figure 14 shows the stress intensity factors of Mode II for Cracks 1, 2, and 3 for different values of the initial crack length, respectively. Based on these

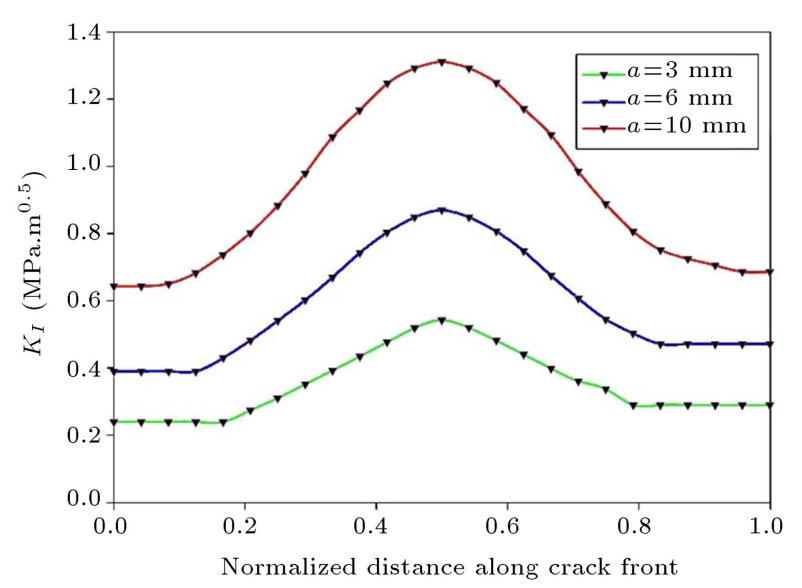

(a)

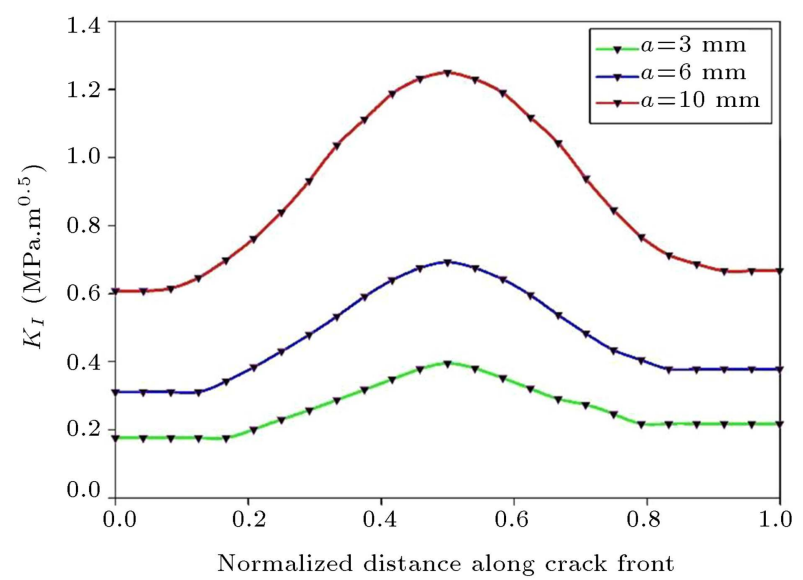

(b)

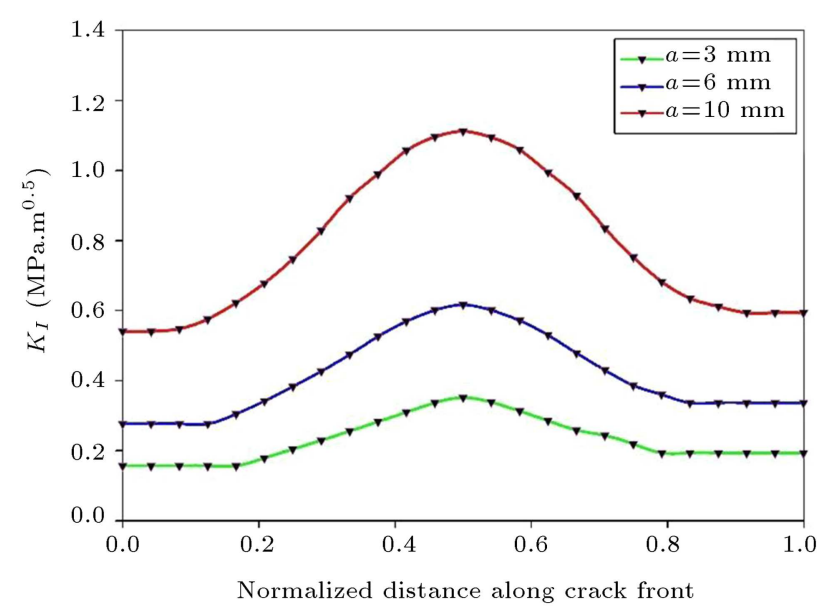

(c)

Figure 13. $K_{I}$ for different initial crack lengths: (a) Crack 1, (b) Crack 2, and (c) Crack 3.

diagrams, cracks of greater length are the reason for an increase in values of the stress intensity factors. As shown in these figures, when the initial length of the crack increases from 3 to $6 \mathrm{~mm}$, no significant change can be observed in the stress intensity factors of Mode II. However, once the initial crack length rises up from 6 to $10 \mathrm{~mm}$, a significant change can be observed 


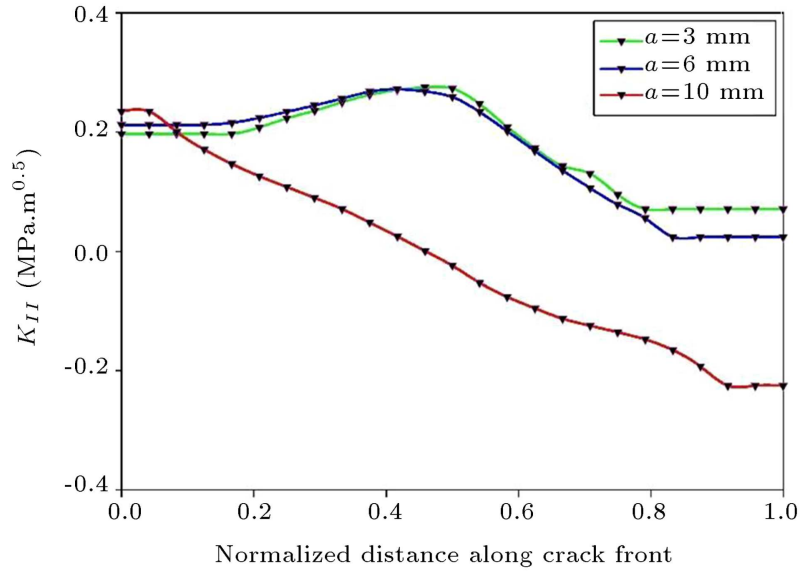

(a)

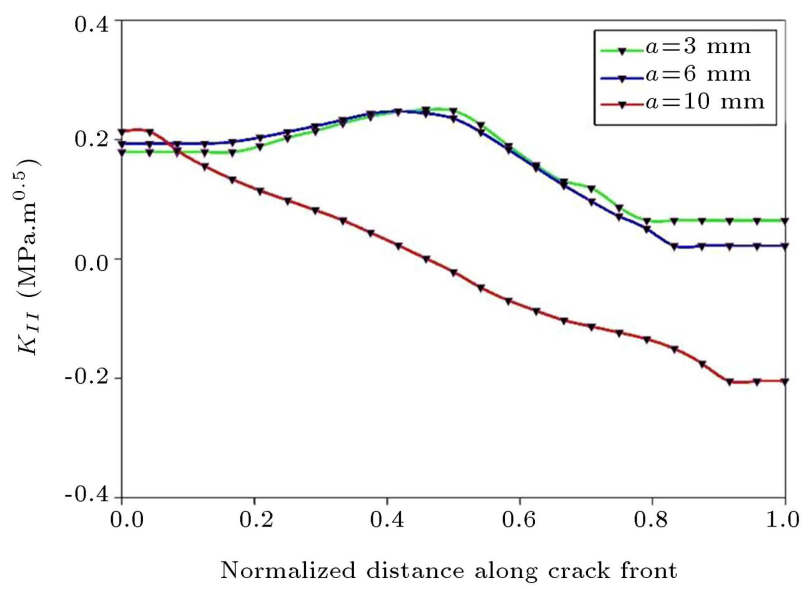

(b)

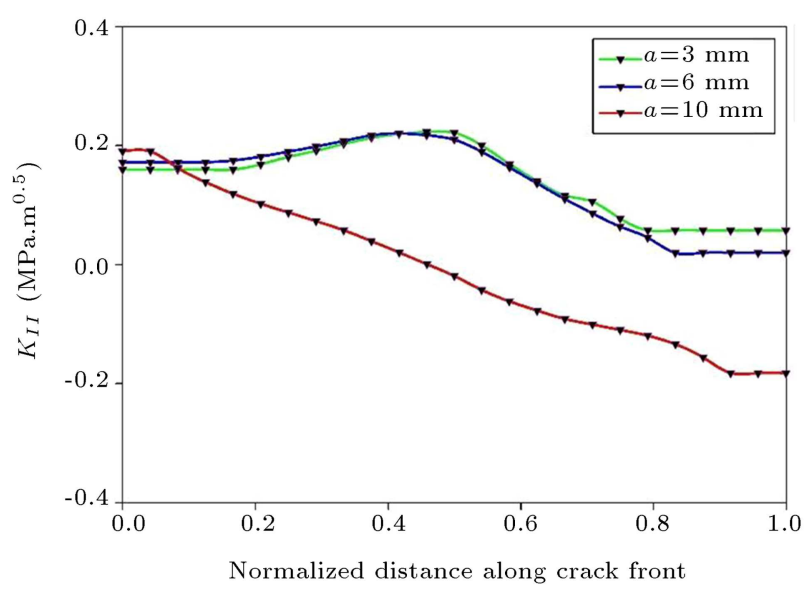

(c)

Figure 14. $K_{I I}$ for different initial crack lengths: (a) Crack 1, (b) Crack 2, and (c) Crack 3.

in this factor. Hence, as the crack length increases, the Mode-II stress intensity factor grows, and it is more significant in cracks of greater initial length.

Figure 15 shows the stress intensity factors of Mode III for Cracks 1, 2, and 3 for different values of the initial crack length, respectively. The stress

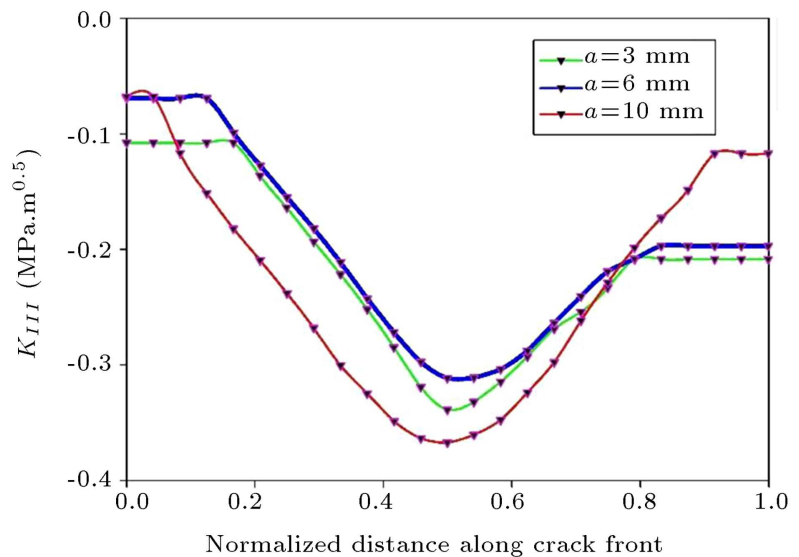

(a)

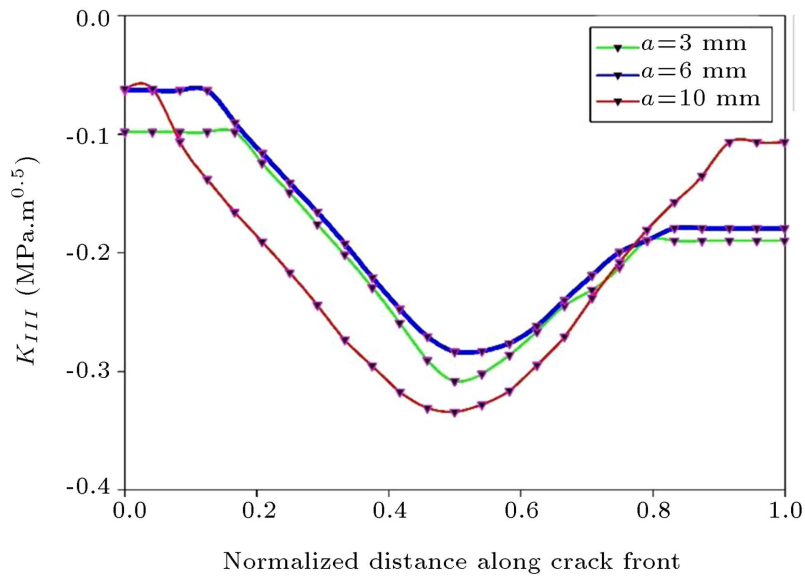

(b)

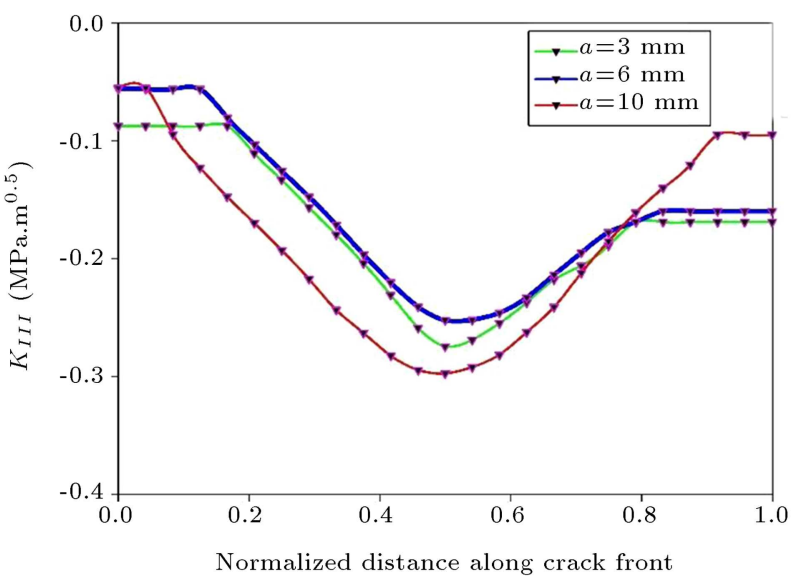

(c)

Figure 15. $K_{I I I}$ for different initial crack lengths: (a) Crack 1, (b) Crack 2, and (c) Crack 3.

intensity factor of Mode III for each of the three crack types increased as the initial crack length increased. In addition, the values of this stress intensity factor for Crack 1 are higher than those of the two other cracks, indicating that Crack 1 is more important than the other two crack types.

With an increase in the crack length, the rate 
of crack growth increases, too. This law applies to all cracks. The increase of the crack growth rate is dependent on different factors such as initial crack angle, initial crack length, and the amount of contact stresses. Since this research is based on altering a parameter while keeping the other influential factors in fatigue crack growth constant, here, the dependency of fatigue life changes on the initial crack length in rail is illustrated in Figure 16.

Considering the results of stress intensity factor analysis under the influence of residual stresses in this subsection and the results without taking into account the residual stresses in the previous subsection, it can be concluded that the stress intensity factors in rail (without residual stress) are less than those in the presence of thermal residual stress and in utilization. In the case of cracks with a length less than $6 \mathrm{~mm}$, the stress intensity factors undergo no significant changes in case of an increase in the initial crack length. However, in the case of cracks with a length more than $6 \mathrm{~mm}$, changes in the initial crack length cause a significant shift in the stress intensity factor.

With regard to the results derived from fatigue life under the influence of residual stresses and results of fatigue life without taking into account the residual stresses in the previous subsection, it can be concluded that fatigue life regardless of residual stress is more than fatigue life with residual stresses. Yet, as the applied stress increases, the difference between these two decreases, because applied stress has higher effect on fatigue life.

Slope of the fatigue life curve in terms of crack length, in the first part and starting point of the curve, is very small over the crack length. Therefore, a small increase in crack length causes a great increase in fatigue life. Hence, the stress intensity factor is more important over cracks of short length than in cracks with greater length. With a look at the analyses conducted, the importance of the effect of residual stresses and crack length in crack growth analysis can be realized. If residual stress is not taken into account, the rail with higher fatigue life is compared to the case where residual stress is taken into account. Moreover, the initial crack length had a great impact on fatigue life in the presence of residual stresses.

\section{Conclusion}

A 3D model was presented in this study for fatigue crack growth and estimating the rail fatigue life. This paper specified the factors that affect crack growth for three types of surface cracks in failure through linear elastic fracture mechanics. Parametric failure analysis was conducted by specialized finite element Franc 3D software. In addition, the effect of the stress distribution in the rail manufacturing process

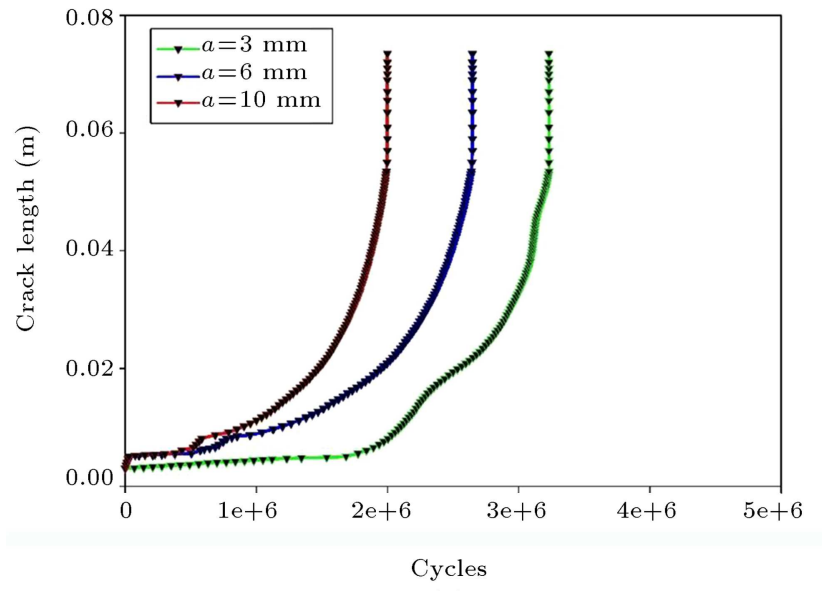

(a)

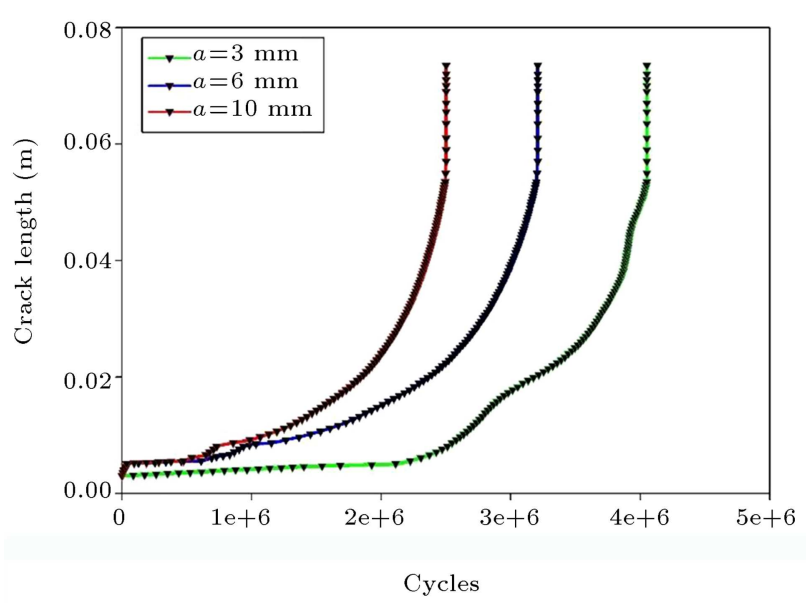

(b)

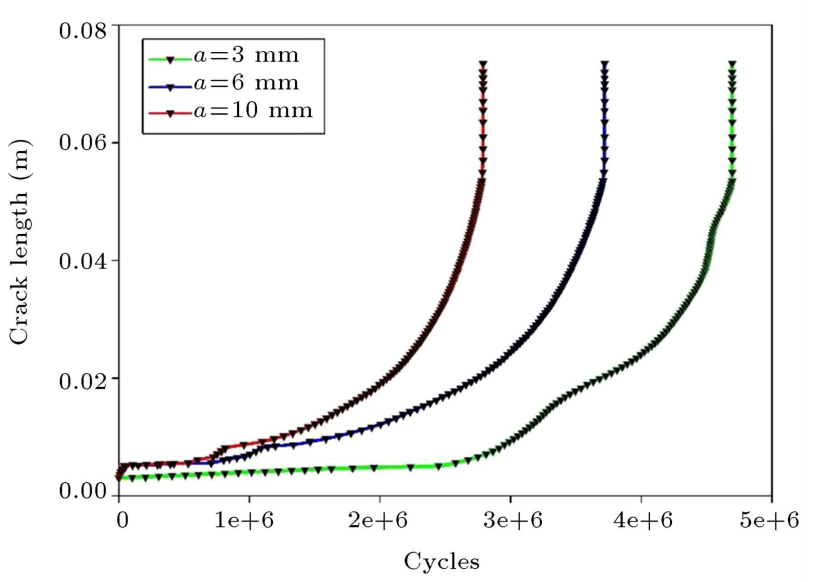

(c)

Figure 16. Initial crack length influence on fatigue life: (a) Crack 1, (b) Crack and 2, (c) Crack 3.

on its contact with the wheel and the stress field created by its contact with the rail and fatigue life were discussed. Based on the results of numerical analysis and comparing them with field observations in Iran railway, the most significant results of this study can be presented as follows: 
1. Comparison of the above-mentioned results indicated that residual stresses caused by the manufacturing process had a significant effect on fatigue life. In addition, hoop residual stress and yield stress accounted for the shear mode with high impact on circumferential crack and also caused the crack to deviate from the main path;

2. Initial crack length plays an important role in fatigue life such that the less this initial length is, the more the fatigue life will be. The initial crack length generally depends on the manufacturing process and wheel/rail contact (utilization); fatigue life may increase with more control on these two areas;

3. With an increase in crack length, the absolute value of $K_{I I} / K_{I}$ increases, thus increasing the initial angle of crack propagation. Changes in the angle that result from varying lengths suggest that the tendency towards moving inward increases with an increase in crack length; in other words, the higher the crack length is, the more probable it is for the crack to become deeper;

4. Stress intensity factors for Crack 1 are higher than those for Cracks 2 and 3 in rail, which is indicative of the importance of surface cracks. In other words, fatigue life for surface cracks in rail is lower than that for cracks in rail head or rail web;

5. Slope of fatigue life curve in terms of crack length in the initial part and along small cracks is very low. In other words, a small increase in crack length leads to a great growth in life. Therefore, the direction of the stress intensity factor along small cracks is considered to be much more important than that of the stress intensity factor along large cracks;

6. By considering the results obtained closely, it can be concluded that as the crack length increases, fatigue life decreases. In addition, it is observed that the ratio of fatigue life changes in Crack 1 is more than that in Cracks 2 and 3.

Relevant topics suggested for further research include examining parameters that affect fatigue life such as wheel/rail coefficient friction, initial crack length, changes in rail profile, rail rigidity, breaking force and its effect on the rail, and structural defects of the rail.

\section{References}

1. Hadipour, M., Alambeigi, F., Hosseini, R., and Masoudinejad, R. "A study on the vibrational effects of adding an auxiliary chassis to a 6-ton truck", Journal of American Science, 7(6), pp. 1219-1226 (2011).
2. Masoudi Nejad, R., Farhangdoost, Kh., and Shariati, M. "Numerical study on fatigue crack growth in railway wheels under the influence of residual stresses", Engineering Failure Analysis, 52, pp. 75-89 (2015).

3. Masoudi Nejad, R. "Using three-dimensional finite element analysis for simulation of residual stresses in railway wheels", Engineering Failure Analysis, 45, pp. 449-455 (2014).

4. Salehi, S.M., Farrahi, G.H., Sohrabpoor, S., and Masoudi Nejad, R. "Life estimation in the railway wheels under the influence of residual stress field", International Journal of Railway Research, 1(1), pp. 53-60 (2014).

5. Ghahremani Moghadam, D., Farhangdoost, Kh., and Masoudi Nejad, R. "Microstructure and residual stress distributions under the influence of welding speed in friction stir welded 2024 aluminum alloy", Metallurgical and Materials Transactions B, 47(3), pp. 2048-2062 (2016).

6. Kwon, S., Seo, J.W., Jun, H.K, and Lee, D.H. "Damage evaluation regarding to contact zones of high-speed train wheel subjected to thermal fatigue", Engineering Failure Analysis, 55, pp. 327-342 (2015).

7. Vakkalagadda, M.R.K., Vineesh, K.P., Mishra, A., and Racherla, V. "Locomotive wheel failure from gauge widening/condemning: Effect of wheel profile, brake block type, and braking conditions", Engineering Failure Analysis, 59, pp. 1-16 (2016).

8. Vakkalagadda, M.R.K., Vineesh, K.P., Mishra, A., and Racherla, V. "Locomotive wheel failure from gauge widening/condemning: Finite element modeling and identification of underlying mechanism", Engineering Failure Analysis, 57, pp. 143-155 (2015).

9. Ringsberg, J.W. and Lindbäck, T. "Rolling contact fatigue analysis of rails including numerical simulations of the rail manufacturing process and repeated wheelrail contact loads", International Journal of Fatigue, 25(6), pp. 547-558 (2003).

10. Skyttebol, A., Josefson, B.L., and Ringsberg, J.W. "Fatigue crack growth in a welded rail under the influence of residual stresses", Engineering Fracture Mechanics, 72(2), pp. 271-285 (2005).

11. Masoudi Nejad, R., Farhangdoost, Kh., and Shariati, M. "Three-dimensional simulation of rolling contact fatigue crack growth in UIC60 rails", Tribology Transactions, 59(6), pp. 1059-1069 (2016).

12. Masoudi Nejad, R., Farhangdoost, Kh., Shariati, M., and Moavenian, M. "Stress intensity factors evaluation for rolling contact fatigue cracks in rails", Tribology Transactions, 60(4), pp. 645-652 (2016).

13. Shariati, M. and Masoudi Nejad, R. "Fatigue strength and fatigue fracture mechanism for spot welds in Ushape specimens", Latin American Journal of Solids and Structures, 13(15), pp. 2787-2801 (2016).

14. Shariati, M., Mohammadi, E., and Masoudi, Nejad R. "Effect of a new specimen size on fatigue crack 
growth behavior in thick-walled pressure vessels", International Journal of Pressure Vessels and Piping, 150, pp. 1-10 (2017).

15. Wong, S.L., Bold, P.E., Brown, M.W., and Allen, R.J. "A branch criterion for shallow angled rolling contact fatigue cracks in rails", Wear, 191(1), pp. 4553 (1996).

16. Murakami, Y., Sakae, C., Hamada, S., Beynon, J.H., and Brown, M.W., Engineering Against Fatigue, A.A. Balkema Publications, Rotterdam (1999).

17. Chue, C.H. and Chung, H.H. "Pitting formation under rolling contact", Theoretical and Applied Fracture Mechanics, 34(1), pp. 1-9 (2000).

18. Masoudi Nejad, R. "Rolling contact fatigue analysis under influence of residual stresses", MS Thesis, Sharif University of Technology, School of Mechanical Engineering (2013).

19. Masoudi Nejad, R., Salehi, S.M., and Farrahi, G.H. "Simulation of railroad crack growth life under the influence of combination mechanical contact and thermal loads", in 3rd International Conference on Recent Advances in Railway Engineering, Iran (2013).

20. Masoudi Nejad, R., Salehi, S.M., Farrahi, G.H., and Chamani, M. "Simulation of crack propagation of fatigue in Iran rail road wheels and effect of residual stresses", In: Proceedings of the 21st International Conference on Mechanical Engineering, Iran (2013).

21. Masoudi Nejad, R., Shariati, M., and Farhangdoost, Kh. "3D finite element simulation of residual stresses in UIC60 rails during the quenching process", Thermal Science, 21(3), pp. 1301-1307 (2017).

22. Masoudi Nejad, R., Shariati, M., and Farhangdoost, Kh. "Effect of wear on rolling contact fatigue crack growth in rails", Tribology International, 94, pp. 118125 (2016).

23. Elber, W. "The significance of fatigue crack closure, in damage tolerance in aircraft structures", ASTM STP, 486, pp. 230-242 (1971).

24. Anderson, T.L., Fracture Mechanics, Fundamentals and Applications, 2nd Ed., CRC press (1994).

25. Newman, J.C. "A crack opening stress equation for fatigue crack growth", International Journal of Fracture, 24(4), pp. 131-135 (1984).

26. Masoudi Nejad, R. "Three-dimensional analysis of rolling contact fatigue crack and life prediction in railway wheels and rails under residual stresses and wear", Ph.D. Thesis, Ferdowsi University of Mashhad, School of Mechanical Engineering (2017).
27. Magel, E., Sroba, P., Sawley, K., and Kalousek, J., Control of Rolling Contact Fatigue of Rails, Center for Surface Transportation Technology, National Research Council Canada (2005).

\section{Biographies}

Reza Masoudi Nejad received the MSc degree from Sharif University of Technology, Iran. He is currently a $\mathrm{PhD}$ student in Mechanical Engineering, Ferdowsi University of Mashhad, Iran. To date, he has published more than 24 journal and 12 conference papers. He has recently published a book named "Mechanical design of electromechanical systems in micro-nano scale" in Sharif University of Technology Publishing. His research interests include finite element, fatigue and fracture mechanics, stresses, fatigue and friction of rolling/sliding, surface science, and residual stress measurement and prediction.

Mahmoud Shariati received his $\mathrm{PhD}$ degree in Mechanical Engineering in 1999 from Tarbiat Modares University, Iran and is currently a Professor of Mechanical Engineering at Ferdowsi University of Mashhad, Iran. To date, he has published more than 124 journal and 64 conference papers. His research interests include fatigue and fracture mechanics, nano-mechanics, stress analysis, and experimental mechanics.

Khalil Farhangdoost obtained his $\mathrm{PhD}$ degree in Mechanical Engineering from McGill University, Montreal, Canada, 1994 and is currently a Professor of Mechanical Engineering at Ferdowsi University of Mashhad, Iran. To date, he has published more than 45 journal and 62 conference papers. His research interests include damage processing of mechanical structures and elements, reliability and life prediction models.

Amir Atrian received his $\mathrm{PhD}$ degree from BuAli Sina University, Iran, 2014. He is currently an Assistant Professor at the Department of Mechanical Engineering, Najafabad Branch, Islamic Azad University, Iran. His research interests are mechanical characterization, metal forming, powder metallurgy, composite, FGM, energy absorption, and finite element modeling. 